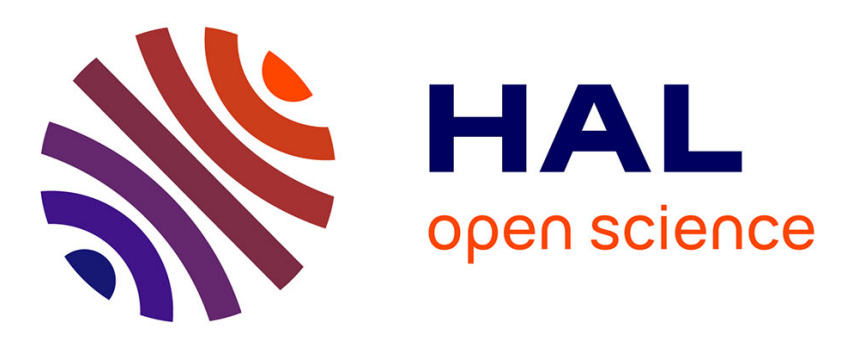

\title{
Simulation of Channel Segregation During Directional Solidification of In-75 wt pet Ga. Qualitative Comparison with In Situ Observations
}

\author{
Ali Saad, Charles-André Gandin, Michel Bellet, Natalia Shevchenko, Sven \\ Eckert
}

\section{To cite this version:}

Ali Saad, Charles-André Gandin, Michel Bellet, Natalia Shevchenko, Sven Eckert. Simulation of Channel Segregation During Directional Solidification of In-75 wt pct Ga. Qualitative Comparison with In Situ Observations. Metallurgical and Materials Transactions A, 2015, Symposium ICASP-4 International Conference on Advanced Solidification Processing, 46 (11), pp.4886-4897. 10.1007/s11661015-2963-8 . hal-01159073

\section{HAL Id: hal-01159073}

https: / hal-mines-paristech.archives-ouvertes.fr/hal-01159073

Submitted on 9 Jan 2017

HAL is a multi-disciplinary open access archive for the deposit and dissemination of scientific research documents, whether they are published or not. The documents may come from teaching and research institutions in France or abroad, or from public or private research centers.
L'archive ouverte pluridisciplinaire HAL, est destinée au dépôt et à la diffusion de documents scientifiques de niveau recherche, publiés ou non, émanant des établissements d'enseignement et de recherche français ou étrangers, des laboratoires publics ou privés. 


\title{
Simulation of Channel Segregation during Directional Solidification of In - 75 wt.\% Ga - Qualitative Comparison with In-Situ Observations
}

\author{
Ali SAAD ${ }^{1)}$, Charles-André GANDIN ${ }^{1)}$, Michel BELLET ${ }^{1)}$, \\ Natalia SHEVCHENKO ${ }^{2)}$, Sven ECKERT ${ }^{2)}$ \\ ${ }^{1)}$ MINES ParisTech, Centre de Mise en Forme des Matériaux, \\ UMR CNRS 7635, CS10207, 06904 Sophia Antipolis, France. \\ E-mail contact: charles-andre.gandin@mines-paristech.fr \\ ${ }^{2)}$ Helmholtz-Zentrum Dresden-Rossendorf, Institute of Fluid Dynamics, \\ P.O. Box 510119, 01314 Dresden, Germany. \\ E-mail contact: s.eckert@hzdr.de
}

\section{Keywords:}

Solidification, Convective plumes, Channel segregation, Freckles, Dendritic Growth

\begin{abstract}
:
Freckles are common defects in industrial casting. They result from thermosolutal convection due to buoyancy forces generated from density variations in the liquid. The present paper proposes a numerical analysis for the formation of channel segregation using the three-dimensional (3D) cellular automaton (CA) - finite element (FE) model [1]. The model integrates kinetics laws for the nucleation and growth of a microstructure to the solution of the conservation equations for the casting, while introducing an intermediate modeling scale for a direct representation of the envelope of the dendritic grains. Directional solidification of a cuboid cell is studied. Its geometry, the alloy chosen as well as the process parameters are inspired from experimental observations recently reported in the literature [2]. Snapshots of the convective pattern, the solute distribution and the morphology of the growth front are qualitatively compared. Similitudes are found when considering the coupled 3D CAFE simulations. Limitations of the model to reach direct simulation of the experiments are discussed.
\end{abstract}




\section{Introduction}

Chemical segregation is of central importance in the casting industry. Many casting defects find their origins in segregation of solute species. The effects of the latter, despite taking place at microstructural scale, can manifest on the casting scale through composition inhomogeneity. It is then referred to as macrosegregation in the literature [3]. A well-known effect of macrosegregation is the non-uniformity of the distribution of the intermetallic phases in industrial alloys. Their amount and shape yet mainly dictate alloy properties and subsequent solutionizing heat treatments are often unable to efficiently counterbalance these casting defects. At intermediate scales, another form of segregation is discerned, the so-called freckle. This defect manifests itself as a composition inhomogeneity that is highly non-isotropic. A typical description of its morphology would consider a channel with a diameter proportional to few primary dendrite arm spacing

and a length that could vary from millimeters to centimeters. These "worm"-like shapes could form during directional solidification of cast parts designed for engine applications, particularly in Nickel-base superalloys [4]-[7]. In the latter situation, the channels are filled with a chain of small equiaxed crystals, thus referring to the term "freckle". In large steel ingots, these channel defects are also related to A- and V- segregates [8].

Considering a binary alloy with a partition coefficient less than unity and having a negative liquidus slope, freckles may form by the following mechanisms: i) solute partitioning occurs at the scale of dendrite arms and solute is rejected in the melt, ii) local composition gradients are intensified resulting in an increase of the solutal buoyancy force in the mushy zone, iii) solute-rich pools are formed, causing segregation chimneys and convective plumes in the melt, iv) which lead to partial remelting and transport of dendrites, continuous solute feeding and locally delayed solidification, and finally v) accumulation of fragments and/or equiaxed crystals in the chimneys before the end of solidification.

Because it is of prime importance to control the occurrence of freckles, several attempts have been made from the late 1960's [9]-[11] to the early 2000's [12] to understand it and characterize it by deriving freckling criteria. These studies are summarized in [13]. One of the reasons for only considering freckling criteria is that direct realistic simulations of the formation of freckles in a casting geometry are still difficult. Indeed, experimental observations show that it requires a satisfying description of the microstructure together with the 3D convective flow controlled by the cooling conditions of the complete cast part [2]. Such information is not accessible yet. Only simulations in representative simple cuboid or cylindrical domains are usually achieved [14]-[17], except when considering small volume casting [18]. They are usually limited to unstable thermosolutal convection without or with little regard to the microstructural features. Considering the spatial resolution of the defect, being for example of the order of the primary dendrite arm spacing, a fluid flow computation in the 3D casting part is also very demanding and not common in the literature.

Among other criteria, the dimensionless Rayleigh number has been identified as a good indicator for the occurrence of channel segregates and freckle defects. The dependence of freckling tendency on the 
Rayleigh number has been studied numerically and compared to experimental observations [12]. Nevertheless, freckling criteria will not be discussed here as the scope of this paper is a comparison of benchmark experiments with direct numerical simulations. The benchmark is a recent work on directional solidification of In $-75 \mathrm{wt}$ \% Ga featuring in-situ X-ray monitoring that was carried out by Shevchenko et al. [2]. The comparison with numerical modeling is paramount for two main reasons: firstly, the in-situ technique allows to follow solidification in real-time and offers visual description of the system behavior: grain morphology, composition evolution, effect on fluid flow in the mushy zone and chimney initiation, as well as other modeling input data such as dendritic and eutectic nucleation undercooling; secondly, an indium-gallium system is more representative of metallic alloy solidification than the widely used organic

systems, e.g. the succinonitrile-acetone mixture that exhibits alloy-like dendritic formation in its growth stage.

The current work intends to apply the 3D CAFE model to show the real need for microstructure information, namely orientation and envelope geometry, to predict channel segregations in process-scale simulations. First, the experimental set-up and conditions are presented. It is followed by a modeling section where the equations are presented for both, the pure macroscopic FE model and the multiscale CAFE model. Finally, results of the model-vs-experiment are discussed for each case in the last section.

\section{Benchmark Experiments}

The solidification experiments were carried out at HZDR using an experimental setup which is explicitly described in reference [2]. The nominal composition of the In $-75 \mathrm{wt} . \% \mathrm{Ga}$ alloy was prepared from 99.99\% In and $99.99 \%$ Ga. The alloy was melted and filled into a hexagonal Hele-Shaw quartz cell with an area of $25 \times 35 \mathrm{~mm}^{2}$ and a gap of $150 \mu \mathrm{m}$ (see Figure 1(a)). Two Peltier elements act as a cooler which was attached to the bottom part of the cell. A second pair of Peltier elements was mounted on the upper part of the solidification cell to heat up the alloy. During the course of solidification, the temperature gradient across the cell and the cooling rate were controlled by a simultaneous and concerted operation of the Peltier heater and cooler. Four miniature K-type thermocouples were contacted to the surface of the cell to monitor the temperature and the temperature gradient. The experiments were carried out at constant cooling rate of $0.01 \mathrm{~K} \mathrm{~s}^{-1}$ and vertical temperature gradients ranging from 1 to $2 \mathrm{~K} \mathrm{~mm}^{-1}$. A lateral temperature gradient arises from the specific hexagonal geometry of the solidification cell. Conical shape of the side walls leads to uniform cooling of the cell. Lateral temperature gradient was measured in the range $0.02-0.5 \mathrm{~K} \mathrm{~mm}^{-1}$. Subsequent variations of the lateral temperature gradient were provided by additional cooling from the sides of the solidification cell. For that purpose, additional metal plates were attached at the side walls of the cell and connected to the Peltier cooler. A microfocus X-ray tube (Phoenix XS225D-OEM) was used to perform the radioscopy. The X-ray observation was performed over a rectangular window of $20 \times 25 \mathrm{~mm}^{2}$. Images were captured with a scan rate of 50 half frames per second and a spatial resolution of ten microns. For reducing the noise level, single images were integrated over a period of $1 \mathrm{~s}$. Solute concentration distribution is derived from the images using the information from the brightness variation. Further information with respect to the experimental hardware, procedure and data analysis can be found in [2], [19]. 


\section{CAFE Model}

\subsection{Macroscopic scale}

\section{Conservation equations}

A general model for solidification accounting for heat and mass exchange in the presence of fluid flow is used. It is based on conservation equations written for energy, momentum, total mass and solute mass assuming a fixed solid phase. Table 1 summarizes the equations of the macroscopic model considering a volume averaging procedure over a representative elementary volume that includes a liquid phase, $l$, with volume fraction $g^{l}$ and a solid phase, $s$, with volume fraction $\quad l$. The first two equations are solved to compute the superficial velocity $\left\langle\boldsymbol{v}^{l}\right\rangle$, and the pressure $p^{l}$. The viscosity of the liquid is chosen constant. The fluid is assumed incompressible with a reference density $f$. Energy conservation is written considering the average volumetric enthalpy of the mixture of the solid and liquid phases, $\langle\rho h\rangle$ $g\langle\rho h\rangle^{s}+g^{l}\langle\rho h\rangle^{l}$. Assuming a constant value for the heat capacity of the solid and liquid phases, $c_{p}$, one can write $\langle\rho h\rangle=\rho c_{p} T+g^{l} \rho L$, where density $\rho$ is simply taken as the constant $\rho_{\text {ref }}$. The average thermal conductivity in the solid-liquid mixture is computed as a function of the intrinsic properties of the phases as $\langle\kappa\rangle=g^{S}\langle\kappa\rangle^{S}+g^{l}\langle\kappa\rangle^{l}$, while constant values are used for each phase. Finally, the solute mass conservation equation is written for a binary alloy. Only the average mass composition of the solute element, $\langle w\rangle$, is computed here. In the absence of solid movement, the transport phase of the solute through the liquid, $\langle w\rangle^{l}$, has to be taken into account.

\section{Constitutive relations}

The liquid density is taken constant, leading to an incompressible Navier-Stokes system of momentum equations. However, the melt density can vary spatially as a function of temperature and average composition, possibly creating thermosolutal convection. The Boussinesq relation accounts for such variations via the thermal and solutal $\beta_{\langle w\rangle}$ expansion coefficients, as follows:

$$
\left(T,\langle w\rangle^{l}\right) \quad \operatorname{ref}\left[1-\beta_{T}\left(T-T_{\text {ref }}\right) \quad\langle w\rangle\left(\langle w\rangle^{l}-\langle w\rangle_{\text {ref }}^{l}\right)\right] \boldsymbol{g}
$$

where $\left(T,\langle w\rangle^{l}\right)$ is a mechanical force in a liquid at nominal density, $f$, created by a temperature and composition difference with respect to a reference temperature, , and reference composition, $\langle w\rangle_{r e f}^{l}$, respectively. Values for the references are simply taken as the liquidus temperature and the nominal composition of the alloy, $\left\langle w_{0}\right\rangle$.

Channel segregation is strongly related to the ratio of buoyancy forces to the interfacial drag force imposed by the dendrites network on the interdendritic liquid. It is imperative thus to model the flow's pressure drop inside the mushy zone using a Darcy law. The latter considers that the mush behaves like a permeable porous medium. However, this permeability may depend not only on liquid fraction but also on a typical length scale describing the dendrites network. When considered isotropic, the permeability tensor reduces to a scalar value given by the Carman-Kozeny model: 
where is the dendrite arm spacing that can be approximated by the average distance between the secondary dendrite arms defined in a growing array of dendrites [20].

\section{Solidification path}

The macroscale approach employs the finite element method to compute the temperature and composition fields at FE nodes. The liquid fraction is then determined directly from the former fields, assuming a linear phase diagram, i.e. linear liquidus with full thermodynamic equilibrium between phases or lever rule approximation. This linear approximation is made available by the dotted line provided in Figure 2. Note that this line defines a phase diagram that seems very different from the correct one. However, this linear fit is only used in a composition region located around the nominal composition of the alloy. It is also worth noticing that the eutectic microstructure is expected to appear at $15.3^{\circ} \mathrm{C}$. However, experimental observations revealed that large eutectic nucleation undercooling was reached, so the eutectic solidification was not reported in the experiments studied [2]. Consequently, the solidification path is computed without accounting for the eutectic microstructure in the present simulations, thus extending the liquidus and solidus lines below the eutectic temperature as sketched with the linear approximations in Figure 2.

\section{Numerical method}

The mass and liquid momentum conservation equations are solved with a variational multiscale approach [21], assuming a fixed solid phase. The conservation equation for solute mass is linearized using a VollerPrakash approximation [22]. An effective heat capacity method is considered to solve the energy conservation equation. Considering macrosegregation taking place during solidification, tabulations of the thermodynamic properties are applied with the approximation of local full equilibrium [23]. This approach yields the advantage of getting exact values for the specific heat of all phases, as well as latent heats for all phase transformations, for any temperature and average composition, as compared with classical resolutions that depend on a constant or a simple function of the temperature and a constant value for the latent heat due to solidification. The conservation equations are solved on an unstructured mesh using the finite element method. More details can be found elsewhere [1], [23]-[25].

\subsection{Microscopic scale}

The CAFE model introduces a grid of regular and structured cubic cells, with a constant size in all space directions, referred to as the cellular automaton (CA) grid. It is different from the unstructured finite element mesh previously mentioned for the solution of the average conservation equations. A typical CA step dimension is smaller than the smallest FE mesh size. The CA grid serves to represent solidification phenomena including nucleation, growth and remelting of the envelope of the primary dendritic grains. Details about the CAFE model can be found in [1], [24], [25]. Cell information, such as the temperature, the average composition or the velocity of the liquid phase, is interpolated from the nodes of the FE mesh. State indices are also defined for each CA cell, providing the presence of liquid or solid phases.

\section{Nucleation}

Initially, cells are in a fully liquid state. In the present situation, random nucleation sites are chosen based on 
a nucleation density, $\mathrm{n}_{\max }$ (expressed in surface density inverse $m^{-2}$ ), at the bottom surface of the geometry in contact with the cooler. Nucleation occurs in a cell only if the latter contains a nucleation site, and when the local undercooling of the cell reaches the critical nucleation undercooling given as input by a Gaussian distribution of mean undercooling $\Delta T_{N}$ with a standard deviation $\Delta T_{\sigma}$. The crystallographic orientation of each grain newly nucleated is also randomly chosen using values of the Euler angles to fully define the three rotations that transform the reference frame to the $\langle 100\rangle$ directions that define the main growth axes of the dendrite trunks and arms. Grain selection is therefore solely controlled by growth competition.

\section{Growth}

Dendrite growth is driven by the chemical supersaturation $\Omega$, which is a dimensionless number proportional to the difference between the liquid composition at the dendrite tip and the melt composition far away from the tip. The higher the supersaturation, the faster the dendrite tip velocity. However, in the presence of a convective fluid, the chemical supersaturation is highly influenced by the intensity and the direction of the flow with respect to the growth direction of the dendrites. In the current model, convection is central in studying formation of channel segregation. Therefore, the purely diffusive Ivantsov relation used to determine the Peclet number $P e$ as function of the supersaturation, is replaced by a modified relation using a boundary layer correlation model that accounts for both the intensity and the misorientation of the liquid velocity with respect to the growth direction of the dendrites [26]. The main parameters for this growth kinetics models are the Gibbs-Thomson coefficient, $\Gamma$, and the diffusion coefficient for Ga in In, D1.

\section{Solidification path}

The CA model gives the presence of the grains in the liquid as well as its growth undercooling. For coupling with macroscopic scale modeling, the fraction of phases needs to be fed back to the FE model. This is now done by accounting for the information provided by the CA model. Thus, the fraction of solid is no longer the consequence of a simple conversion of the temperature and composition assuming thermodynamic equilibrium. It also includes the solidification delay due to the kinetics of the development of the grains as detailed elsewhere [1].

\section{Numerical method}

Both the finite element mesh and the cellular automaton grid play a role in predicting channel segregation inasmuch as this type of defect originate from interplays between hydrodynamic instabilities on the scale of the dendrites and macroscopic flows defined by the geometry of the experimental cell [2]. One has to respect a small maximum FE mesh size, comparable to the dendrite arm spacing. With such an element size, composition gradients giving rise to solutal buoyancy forces can be captured. This limits consequently the CA cell size, as a minimum number of cells is required in each finite element. In the array of simulations that will be presented in the next section, the value of $\lambda_{2}$ was considered. We have chosen a fixed mesh element size of $2 \lambda_{2}$ and a CA cell size of $\lambda_{2} / 2$. An average of 4 CA cells per unit length of a finite element is enough to accurately compute the development of the grain envelopes together with the solutal, thermal and mechanical interactions. 


\section{Results}

The focus of the present paper is on a qualitative comparison between numerical simulation and experiment. The experimental cell geometry shown in Figure 1 is hexagonal. With adiabatic lateral sides, it results in a bending of the isotherm surfaces as shown in [2]. The metallic cooling plates shown in Figure 1 partly compensate for this effect. However, a residual horizontal component of the temperature gradient remains. To qualitatively replicate this effect while simplifying the cell geometry, a $22 \times 22 \times 1 \mathrm{~mm}^{3}$ cuboid cell is considered with small cooling fluxes on its lateral vertical side surfaces computed using a constant heat transfer coefficient, $h_{c}$, and a constant environment temperature, $T_{\text {ext }}$. Temperatures at the bottom and top surfaces, respectively $T_{\text {top }}$ and $T_{\text {bottom }}$, are imposed in a way to maintain a constant vertical gradient, G, thus linearly decreasing over time with the same cooling rate R. Both square faces of the geometry, having an area of $22 \times 22 \mathrm{~mm}^{2}$, are adiabatic. In spite of taking cell dimensions similar to benchmark experiments presented above, the cell thickness is increased from $150 \mu \mathrm{m}$ to $1 \mathrm{~mm}$. This facilitates the computation and will later be subject to discussion. Materials properties are provided in Table 2 while initial and boundary conditions are given in Table 3. A series of computations is performed to understand the influence of process parameters on the final macrosegregation pattern. In directional growth, the main parameters are the vertical temperature gradient, G, and the cooling rate, R, since they control the isotherms speed. However, the effect of a higher lateral cooling is also considered below by increasing the heat transfer coefficient, $h_{c}$. Finally, the grain structure is another crucial parameter that drastically changes the analysis inasmuch as growth undercooling is fundamental to determine the onset of solidification. The computation cases used in this study are presented in Table 3. The label of each case allows direct access to the simulation parameters as explained in the caption. Values for these parameters are inspired from the above experiments [2]. Initial conditions consider a quiescent liquid at uniform composition given by the nominal alloy composition $\left\langle w_{0}\right\rangle$. The temperature field is also initially uniform at a temperature averaged between the top and bottom initial values provided in Table 3. It has been checked that a uniform temperature gradient is swiftly reached, and that the unsteady regime to settle a vertical temperature gradient does not affect the phenomena studied. For simulations with grain structures, boundary conditions for nucleation at the bottom horizontal $22 \times 1 \mathrm{~mm}^{2}$ surface are kept constant as given in Table 3.

\subsection{FE simulations}

The first case labeled FE_G1R1L0 is a reference case that features a low gradient (G1), low cooling rate (R1), and without any lateral cooling (L0), ensuring that isotherms retain a planar shape. These simulation parameters defined in Table 2, result in a negligible fluid flow reaching a maximum velocity of $4 \cdot 10^{-8} \mathrm{~m} \mathrm{~s}^{-1}$ in the bulk. Accordingly, the solidification front remains stable and follows the planar isotherms; no convective plumes are observed. The average composition field is thus only little modified in the mushy zone as shown in Figure 3 (mind the values of the scale limits). It is concluded that velocity in the bulk is not high enough to initiate instabilities. In the next case, FE_G1R1L1, a cooling flux with a constant and very low value of the heat transfer coefficient is imposed on both vertical lateral surfaces to initiate a downward fluid flow by thermal buoyancy. Once solidification starts, solute-rich regions start to appear on 
the sides of the domain. Despite the visible concentration difference between these lateral regions and the central mush seen in Figure 3, their diffuse and uniform aspect indicates no resemblance to channel segregations. We keep the same configuration but increase the vertical gradient from $0.2 \mathrm{~K} \mathrm{~mm}^{-1}$ (G1) to $1.5 \mathrm{~K} \mathrm{~mm}^{-1}(\mathrm{G} 2)$ in the case FE_G2R1L1. The isotherms become closer to each over hence reducing the depth of the mushy zone for the same time increment compared to the preceding case. The rejected gallium solute locally accumulates at several different positions in the mushy zone, stemming from the base of the cell, with a maximum of $0.7 \mathrm{wt} . \% \mathrm{Ga}$ above nominal composition. This is the consequence of segregation of gallium-rich liquid being lighter than the above liquid bulk and creating an upward buoyancy force. The positive segregation and subsequent Ga-rich chimneys then rise up with an upward component of the liquid velocity slightly greater than $1 \mathrm{~mm} \mathrm{~s}^{-1}$.

Figure 4 gives a series of snapshots for case FE_G2R1L1 at three different times. Among the two clear distinct plumes that are visible at $250 \mathrm{~s}$ in Figure 3, only one has led to the formation of a segregated channel that remains in Figure 4 at $500 \mathrm{~s}$. In fact, an animation between $250 \mathrm{~s}$ and $500 \mathrm{~s}$ (not shown here) reveals that one plume vanishes, thus permitting the first one to further develop. A second segregated channel is also seen on the left-hand-side of the cell. These two channels are stable for a long time since they remain at time $1000 \mathrm{~s}$. However, the left-side channel develops further to become the main one at $1500 \mathrm{~s}$, while the mid-width channel decreases in intensity, changes orientation and subsequently disappears (not shown here). Thus, the birth and death of very few channels is observed in this simulation, mainly due to solutal instability, as the temperature field shown in Figure 4 clearly remains stable despite the low lateral heat flux. As shown in Figure 3, instability is yet required to create these chemical plumes and channels. Here, it is created by a very small lateral heat flow but other sources of instability could be involved, as shown with the grain structure in the next section.

\subsection{CAFE simulations}

Knowing that the configuration in FE_G2R1L1 produces segregated channels, the same set of parameters is first used for case CAFE_G2R1L1 by adding the effect of the grain structure using the CAFE model. Results are accessible in Figure 5 for comparison with Figure 4. A striking difference is seen: the composition maps become more perturbed as shown by the formation of numerous plumes when coupling with grain structure is active. The growing front displayed on the grain structure at the right-most column of Figure 5 dictates the leading position of the mushy zone shown in the third column. Note that each color corresponds to one grain, with 17 grains having nucleated at the cell's bottom surface. However, comparison of the solid fraction maps between Figure 4 and Figure 5 at the same times reveals a delay in the growing front position. Values of the nucleation parameters in Table 3 are such that few grains rapidly form below the nominal liquidus isotherm. The delay is therefore not due to the nucleation undercooling but to the growth undercooling of the dendrite tips. It should be noticed that, the growth front driven by undercooling in Figure 5 also forms with a higher initial solid fraction and hence larger solute segregation occurs at the front. This effect, together with instabilities of the composition field, is caused by a more perturbed fluid flow and more plumes as observed in CAFE_G2R1L1 compared to FE_G2R1L1. Such observations fit to the complicated fluid and solute flow patterns typically occurring in the experiments as 
shown in Figure 6. It becomes obvious that the consideration of grain structure and growth undercooling are vital to accurately simulate chimneys in these experiments. The reasons for the instabilities are discussed hereinafter. In the present 3D CAFE simulation, each grain is associated with a crystallographic orientation. The growth kinetics is only given for the <100> crystallographic directions at the grain boundaries with the liquid. The CA growth model is based on the hypothesis that, in a quiescent liquid of uniform temperature distribution and composition, the grain envelop should reproduce an octahedral grain shape with main directions given by the six <100> directions. In the present situation where complicated fields are present for temperature, composition and liquid velocity, each grain envelope with different crystallographic orientation adapts differently to its local environment. Thus, the local undercooling of the front varies everywhere. Such variations are within few degrees here, but this is sufficient to create some irregularities on the growth front, as seen on the grain structure in Figure 5. Apart from that, these variations are linked to the position of the instabilities for the chemical and liquid velocity fields, thus demonstrating the full coupling between the CA and FE models.

\section{Effect of vertical temperature gradient}

The influence of diverse process parameters can now be considered in context of the grain structure. The effect of the vertical temperature gradient is shown by comparing the previous case CAFE_G2R1L1 with case CAFE_G1R1L1. The temperature gradient is decreased about 7 times here, from $\mathrm{G} 2=1.5 \mathrm{~K} \mathrm{~mm}^{-1}$ to $\mathrm{G} 1=0.2 \mathrm{~K} \mathrm{~mm}^{-1}$. In fact, both cases share almost all traits with respect to flow patterns and velocity magnitude in the bulk. Main differences are yet seen regarding the dynamics of the plumes shown in Figure 7. In the case of a low temperature gradient (G1), the solidification front cannot maintain a shape as smooth as for the case of a large temperature gradient $(\mathrm{G} 2)$ : the solute gradient in the liquid of the mushy zone (basically following the lever rule approximation for a given temperature) decreases, leading to a lower gradient of the solutal buoyancy force. In turn, more solute accumulates close to the front and locally reduces the growth velocity, thus creating larger "valleys" or steps with higher solute content. The irregular geometry of the front is also influenced by the dendrite tip growth kinetics model. The velocity of the isotherms is the ratio of the cooling rate, $\mathrm{R}$, to the temperature gradient, G. Consequently, the isotherm velocity in case G1 is larger than in G2, since cooling rate, R1, is the same in both cases. Moreover, because the dendrite tip velocity is a monotonously increasing function with the undercooling [26], the undercooling for CAFE_G1R1L1 is larger than for CAFE_G2R1L1. Height differences of the growth front are proportional to the variations of the undercooling by the temperature gradient. Therefore, this forms larger steps on the growth front for case G1 compared to G2. The chimney extends deeper in the mushy zone when the temperature gradient increases. This is confirmed by both the simulation results shown in Figure 7 as well as the experimental observations. Another remarkable phenomenon is also observed in the low gradient case: a "pulsing" mechanism in CAFE_G1R1L1 where a series of solute-rich liquid pockets are observed one above the other. This corresponds to a repeated and localized strong spatial variation of the liquid velocity field outside the mushy zone, regularly thrusting away small plumes. These pulses are roughly similar to each other in size and exit speed, creating thus a very regular pattern during some time. In case of a high temperature gradient (case CAFE_G2R1L1) this phenomenon is barely seen. In fact, the 
pattern shown in Figure 7 is more typical, with continuous plume rising from the mushy zone and reaching the top of the domain. However, such regular plume is the initial and final pattern seen for low gradient before the pulsing regime. Similar observations have been made in the experiments too. Figure 8(a) displays the phenomenon of the "pulsing" plumes, which could be explained by the following mechanisms. The permeability of the mushy zone and the narrow gap of the solidification cell obstruct the feeding of the plumes by solute. A critical solute concentration has to be accumulated at a specific location in order to trigger the formation of a rising plume. An interim drop of the solute concentration below such a threshold would interrupt the plume. Flow instabilities can be another reason for the peculiar shape of the plumes. Figure 8 (b) shows a pronounced continuous plume. The same plume can be seen a few seconds later in Figure 8(c). The plume structure becomes unstable; one can observe an indentation of streamlines followed by a mixing of rising solute-rich liquid with descending In-rich fluid. This mechanism also causes a noncontinuous structure of the plumes.

\section{Effect of cooling rate}

The next parameter studied is the cooling rate, corresponding to case CAFE_G1R2L1. A snapshot of the composition map and the corresponding vertical component of the velocity field are given in Figure 9. We see a similarity with case CAFE_G1R1L1 in Figure 7 with respect to the buckled interface between the liquid and the mushy zone as well a plume pulsing effect when a low temperature gradient is applied. On the other hand, segregation inside the mush is more irregular with more pronounced patterns reaching a larger depth. One could distinguish alternating V-and A-shapes patterns in the mushy zone. As for case CAFE_G1R1L1, these patterns are created by a network of pulsing plumes formed by the steps created on the delocalized growth front due to the low temperature gradient. However, these considerations are not sufficient to explain the shape of the growth front. The reason for the protuberances created at the tips of the $\mathrm{V}$-shape is the presence of a descending bulk liquid with a low composition seen by the growth front. It infers that favorable growth conditions are created for a higher working temperature since the dendrite tip undercooling decreases for facing liquid flow and a lower composition; the growth rate is given by the isotherm velocity. The growth front thus adjusts its position to catch up with the corresponding isotherm, the latter being located at the tips of the V-shape, i.e. the outmost advanced position of the growth front. It also means that the $\mathrm{V}$-shape angle depends on the size and intensity of the convection loops above the front. When the steps are formed on the growth front, the plumes exiting the mushy zone follow a direction normal to the front. They are inclined towards each other above the V-shape. As a result, they may join and form a larger plume as seen in Figure 7 CAFE_G1R1L1, thus forming larger and more stable chimneys. The other observation in Figure 9 is the existence of stable regions of the growth front. For instance, this is seen in between the two V-shape forming or on the right-hand-side of the cell. The reason for this stability is the inversion of the composition gradient located ahead. Animation shows that solute coming from the top of the cell is responsible for this accumulation, creating a layering that provides a stabilization effect above the mushy zone. This is verified by the vertical component of the superficial velocity also made available in Figure 9. It is negative outside the path of the plumes. A resulting concurrent effect is the formation of the A-shape segregates in between the V-shape patterns seen in Figure 9. Finally, it can be 
observed that these patterns are sustained longer compared to Figure 7 CAFE_G1R1L1 because, at high cooling rate, the flow in the mushy zone is decreased due to a faster solidification. This is the same effect as described for the large gradient configuration in Figure 7 CAFE_G2R1L1.

It is not clear how these observations could be compared with the A- and V-shapes segregates reported steel ingots [8]. Despite the fact that macrosegregation is the main phenomenon leading to these patterns, there has not been a clear explanation yet in the literature for their formation. However, for steel casting, the $\mathrm{A}$ and $\mathrm{V}$ patterns are believed to form concomitantly. Further investigations would thus be required to quantify the consequences of thermosolutal instabilities simulated here for an In $-75 \mathrm{wt} \% \mathrm{Ga}$ alloy and check their possible correlation with experimental observations in steel casting.

\section{Effect of lateral temperature gradient}

The previous simulations show the effect of cooling rate and temperature gradient on the survival of segregation patterns deep in the mushy zone. Another simulation is performed by increasing the cooling rate using higher heat flux extracted from the vertical side boundaries. This is achieved in case CAFE_G1R1L2 where the heat transfer coefficient reaches $500 \mathrm{~W} \mathrm{~m}^{-2} \mathrm{~K}^{-1}$. As a consequence of the large cooling from the sides, the temperature gradient is no longer vertical. A distinct flow due to thermal buoyancy is created, driving a cold liquid downwards near the sides of the cell. Under the influence of these 2 main convection loops, all segregation plumes tend to regroup in the middle of the domain, forming a larger central plume, as seen in the composition map at $450 \mathrm{~s}$ in Figure 10. However, this regime occurs at times earlier than $500 \mathrm{~s}$, where the effect of thermally induced buoyancy forces is prevailing, feeding the convection loops. Approximately $500 \mathrm{~s}$ later, the mushy zone has extended, favoring the segregation mechanical forces i.e. $\rho_{\text {ref }}\left(1-\beta\langle w\rangle_{l} \Delta\langle w\rangle^{l}\right) \boldsymbol{g}$, rather than the thermal mechanical forces, $\rho_{\text {ref }}\left(1-\beta_{T} \Delta T\right) \boldsymbol{g}$. Figure 10 shows the corresponding composition maps with stable segregated channels at about $1000 \mathrm{~s}$ that also remain at $1500 \mathrm{~s}$. The solidification front then tends to form a concave shape at the center of the cell, thus partially revealing the form of the isotherms toward the cell center. The stable pattern in the center of Figure 10 is similar to the plateau seen in the center in Figure 9, defining an A-shape. As stated before, it is an inactive region with respect to plume initiation due to the inversion of the solute composition gradient. In other words, the high gallium concentration at the top of the cell causes indium, which is the heavier species, to accumulate and be partially trapped between the highly permeable mushy walls, thus creating a stable flow configuration. Outside of the plateau, 2 plumes are observed from the prominent instabilities of the growth front, adopting diverging directions. This is also observed at the center of the cell in Figure 9 on each side of the A-shape segregate. These plumes in Figure 10 lead to the formation of two stable channels.

The corresponding situation in the experiment is shown in Figure 11. The chimneys on both sides and the plateau in between can be clearly recognized. The additional cooling at the side walls produces two flow vortices between the side wall and the strong convective plumes above the chimneys. The central part of the sample remains almost unaffected by the additionally driven thermal convection. This area is characterized by the occurrence of a number of smaller convective plumes. 


\section{Conclusion}

- Demonstration of the possibility to model channel segregation with the 3D CAFE model was given for a benchmark experimental configuration with in-situ observations that corresponds to the In - $75 \mathrm{wt} . \% \mathrm{Ga}$ alloy available in the literature [2].

- V-shape and A-shape segregates were produced as an output of the simulations that are favored by a low temperature gradient or a high cooling rate. The mechanism for their occurrence was provided. Observations show that it was accompanied by pulsing mechanisms and destabilization of the growth front. To our knowledge, it is the first proposed explanation in the literature for V-shape and A-shape segregates. It is still unclear if these patterns are linked to the well-known similarly named defects in casting of steel ingots.

- Limitations of the model still remain to provide a direct simulation of the experiments, as achieved for other in-situ experiments [27], [28]. They mainly concern the cell geometry. To go down to a $150 \mu \mathrm{m}$-thick cell would require more computational resources because a smaller FE mesh size is required, with consequences on the total number of elements for the representation of the whole domain. The other limitations are on the overall shape of the experimental solidification cell that is hexagonal, as well as on the characterization of the cooling conditions that could be refined.

- Another possibility for model improvement is to implement an anisotropic permeability model for the computation of the flow in the mushy zone. In such a case, the dissipative drag force exerted on the liquid in the dendrites vicinity is modified by their orientation. Auburtin and coworkers [29] performed directional solidification tests with tilt angles and results showed that channel formation depends on the growth angle.

- A qualitative comparison between numerical simulation and experiment gives a fairly good agreement. Though, different cell dimensions and cooling conditions have been considered both simulation and experiment show distinct features of the process, such as a complicated flow structure in form of a multitude of plumes influencing each other, a "pulsing" behavior of the plumes, or the occurrence of solute-enriched zones in the upper mushy zone beneath dominating plumes. These chimneys can exhibit a V- or A-shape.

The next step of the work concerns a quantitative comparison between numerical prediction and experiment. For that purpose, a new series of experiments and model improvements are being considered. 


\section{References}

[1] T. Carozzani, C.-A. Gandin, H. Digonnet, M. Bellet, K. Zaidat, and Y. Fautrelle, "Direct Simulation of a Solidification Benchmark Experiment," Metall. Mater. Trans. A, vol. 44, no. 2, pp. 873-887, Feb. 2013.

[2] N. Shevchenko, S. Boden, G. Gerbeth, and S. Eckert, "Chimney Formation in Solidifying Ga-25wt pct In Alloys Under the Influence of Thermosolutal Melt Convection," Metall. Mater. Trans. A, vol. 44, no. 8, pp. 3797-3808, Aug. 2013.

[3] C. Beckermann, "Modelling of macrosegregation: applications and future needs," Int. Mater. Rev., vol. 47, no. 5, pp. 243-261, 2002.

[4] A. F. Giamei and B. H. Kear, "On the nature of freckles in nickel base superalloys," Metall. Trans., vol. 1, no. 8, pp. 2185-2192, Aug. 1970.

[5] M. C. Schneider, J. P. Gu, C. Beckermann, W. J. Boettinger, and U. R. Kattner, "Modeling of microand macrosegregation and freckle formation in single-crystal nickel-base superalloy directional solidification," Metall. Mater. Trans. A, vol. 28, no. 7, pp. 1517-1531, Jul. 1997.

[6] C. Beckermann, J. P. Gu, and W. J. Boettinger, "Development of a freckle predictor via rayleigh number method for single-crystal nickel-base superalloy castings," Metall. Mater. Trans. A, vol. 31, no. 10 , pp. 2545-2557, Oct. 2000.

[7] P. D. Genereux and C. A. Borg, "Characterization of Freckles in a High Strength Wrought Nickel Superalloy," presented at the Superalloys 2000, Warrendale, PA, 2000, pp. 19-27.

[8] E. J. Pickering, "Macrosegregation in Steel Ingots: The Applicability of Modelling and Characterisation Techniques," ISIJ Int., vol. 53, no. 6, pp. 935-949, 2013.

[9] M. C. Flemings and G. E. Nereo, "Macrosegregation: Part I," Trans. Metall. Soc. AIME, vol. 239, pp. 1449-1461, 1967.

[10] M. C. Flemings, R. Mehrabian, and G. E. Nereo, "Macrosegregation: Part II," Trans. Metall. Soc. AIME, vol. 242, pp. 41-49, 1968.

[11] M. C. Flemings and G. E. Nereo, "Macrosegregation: Part III," Trans. Metall. Soc. AIME, vol. 242, pp. 50-55, 1968.

[12] J. C. Ramirez and C. Beckermann, "Evaluation of a rayleigh-number-based freckle criterion for Pb-Sn alloys and Ni-base superalloys," Metall. Mater. Trans. A, vol. 34, no. 7, pp. 1525-1536, Jul. 2003.

[13] P. B. L. Auburtin, "Determination of the influence of growth front angle on freckle formation in superalloys," University of British Columbia, Vancouver, BC, Canada, 1998.

[14] S. D. Felicelli, J. C. Heinrich, and D. R. Poirier, "Simulation of freckles during vertical solidification of binary alloys," Metall. Trans. B, vol. 22, no. 6, pp. 847-859, Dec. 1991.

[15] S. D. Felicelli, D. R. Poirier, and J. C. Heinrich, "Modeling freckle formation in three dimensions during solidification of multicomponent alloys," Metall. Mater. Trans. B, vol. 29, no. 4, pp. 847-855, Aug. 1998.

[16] J. Guo and C. Beckermann, "Three-Dimensional Simulation of Freckle Formation During Binary Alloy Solidification: Effect of Mesh Spacing," Numer. Heat Transf. Part Appl., vol. 44, no. 6, pp. 559-576, 2003.

[17] F. Kohler, "Peritectic solidification of Cu-Sn alloys: microstructure competition at low speed," EPFL, 2008.

[18] J.-L. Desbiolles, P. Thévoz, M. Rappaz, and D. Stefanescu, "Micro-Macrosegregation Modeling in Casting: A Fully Coupled 3D Model," presented at the Modeling Of Casting, Welding And Advanced Solidification Processes - X, 2003, pp. 245-252.

[19] S. Boden, S. Eckert, B. Willers, and G. Gerbeth, "X-Ray Radioscopic Visualization of the Solutal Convection during Solidification of a Ga-30 Wt Pct In Alloy," Metall. Mater. Trans. A, vol. 39, no. 3, pp. 613-623, Mar. 2008.

[20] J. A. Dantzig and M. Rappaz, Solidification. EPFL Press, 2009.

[21] E. Hachem, B. Rivaux, T. Kloczko, H. Digonnet, and T. Coupez, "Stabilized finite element method 
for incompressible flows with high Reynolds number," J. Comput. Phys., vol. 229, no. 23, pp. 86438665, Nov. 2010.

[22] V. R. Voller, A. D. Brent, and C. Prakash, "The modelling of heat, mass and solute transport in solidification systems," Int. J. Heat Mass Transf., vol. 32, no. 9, pp. 1719-1731, Sep. 1989.

[23] A. Saad, C.-A. Gandin, and M. Bellet, "Temperature-based energy solver coupled with tabulated thermodynamic properties - Application to the prediction of macrosegregation in multicomponent alloys," to be submitted, 2014.

[24] T. Carozzani, H. Digonnet, and C.-A. Gandin, "3D CAFE modeling of grain structures: application to primary dendritic and secondary eutectic solidification," Model. Simul. Mater. Sci. Eng., vol. 20, no. 1, p. 015010, Jan. 2012.

[25] T. Carozzani, C.-A. Gandin, and H. Digonnet, "Optimized parallel computing for cellular automatonfinite element modeling of solidification grain structures," Model. Simul. Mater. Sci. Eng., vol. 22, no. 1, p. 015012, Jan. 2014.

[26] C.-A. Gandin, G. Guillemot, B. Appolaire, and N. T. Niane, "Boundary layer correlation for dendrite tip growth with fluid flow," Mater. Sci. Eng. A, vol. 342, no. 1-2, pp. 44-50, Feb. 2003.

[27] G. Guillemot, C.-A. Gandin, and M. Bellet, "Interaction between single grain solidification and macrosegregation: Application of a cellular automaton-Finite element model," J. Cryst. Growth, vol. 303, no. 1, pp. 58-68, May 2007.

[28] G. Reinhart, C.-A. Gandin, N. Mangelinck-Noël, H. Nguyen-Thi, J.-E. Spinelli, J. Baruchel, and B. Billia, "Influence of natural convection during upward directional solidification: A comparison between in situ X-ray radiography and direct simulation of the grain structure," Acta Mater., vol. 61, no. 13, pp. 4765-4777, Aug. 2013.

[29] P. Auburtin, T. Wang, S. L. Cockcroft, and A. Mitchell, "Freckle formation and freckle criterion in superalloy castings," Metall. Mater. Trans. B, vol. 31, no. 4, pp. 801-811, Aug. 2000.

[30] J. O. Andersson, T. Helander, L. Höglund, P. F. Shi, and B. Sundman, "Thermo-Calc and DICTRA," Comput. Tools Mater. Sci., vol. 26, pp. 273-312.

[31] TCBIN: TC Binary Solutions Database, version 1.0. Stockholm, SE: Thermo-Calc Software AB, 2006. 


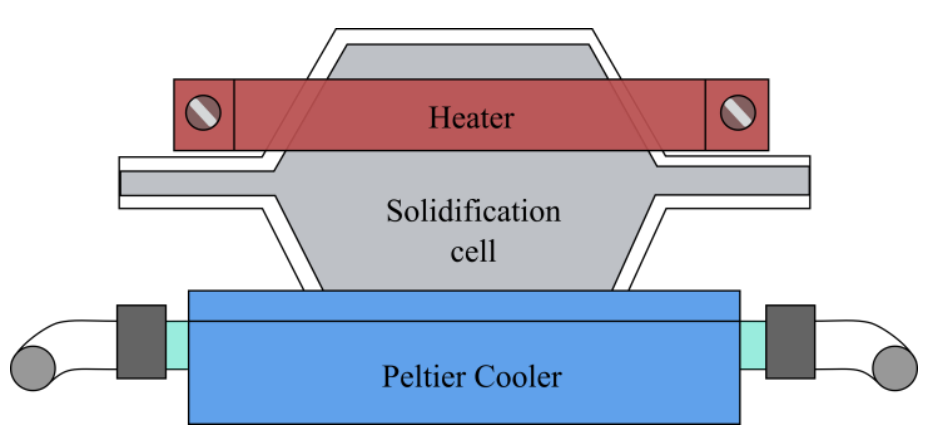

(a)

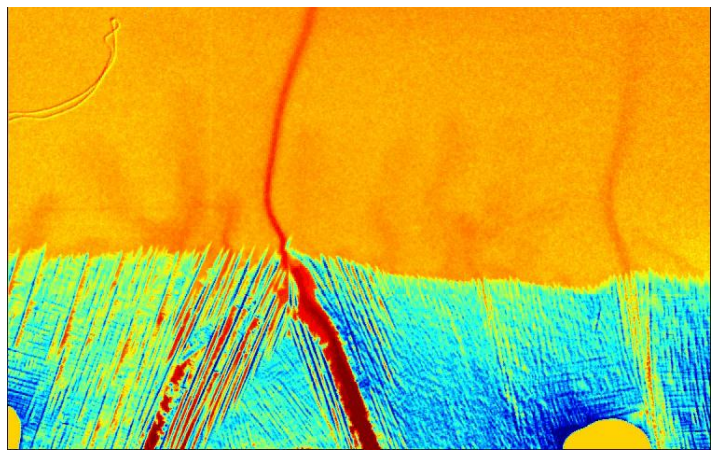

(b)

Figure 1: Illustration of the benchmark experiments for in-situ observation of segregated channels using X-Ray radiography with (a) a schematic of the cell and (b) a typical image of the microstructure formed during directional solidification of an In - 75 wt.\% Ga alloy [2] 


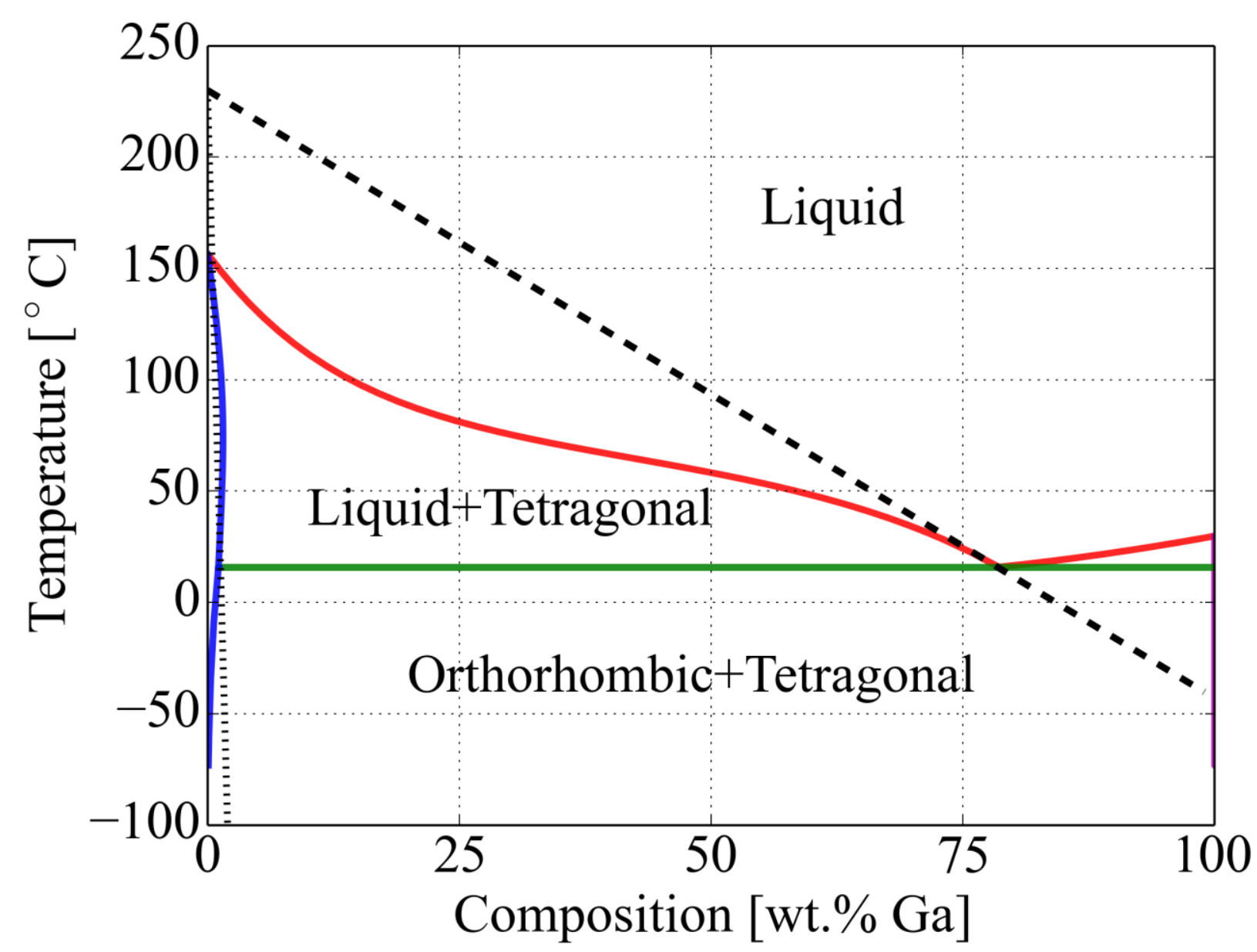

Figure 2: Binary phase diagram of the In-Ga system [30], [31] and its approximation for solidification studies with an In - 75 wt.\% Ga alloy. The dashed and dotted lines are linear liquidus and solidus approximations near the nominal composition. 
FE_G1R1L0

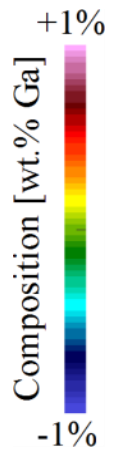

FE G1R1L1

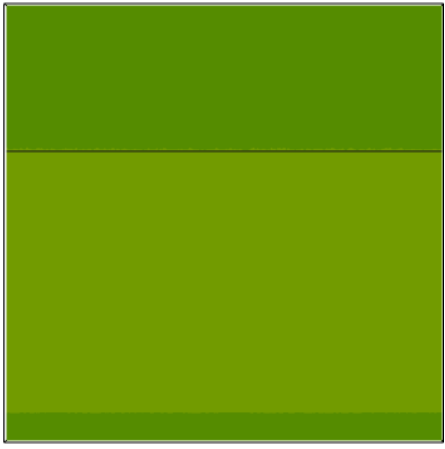

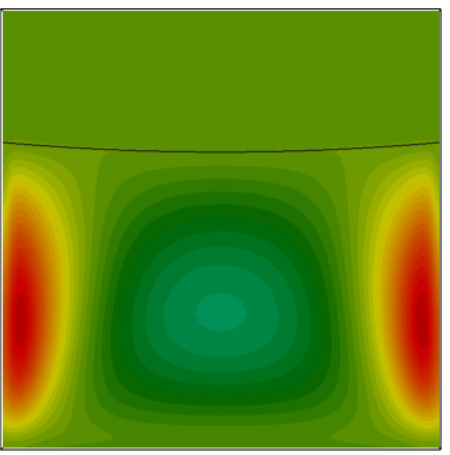

FE_G2R1L1

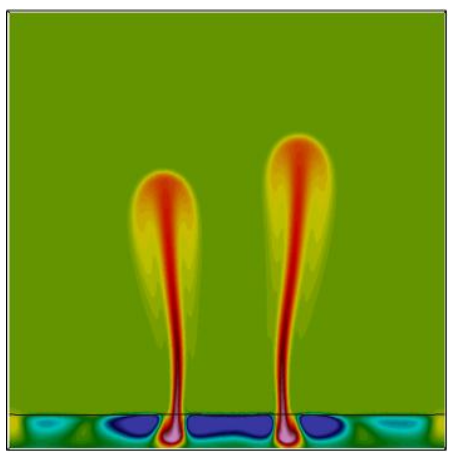

Figure 3: Average composition field at $250 \mathrm{~s}$ for the $3 \mathrm{FE}$ cases showing the influence of the process parameters on the tendency to form channel segregation and convective plumes. The black line represents the liquidus isotherm given in Table 1. 
Composition [wt.\% Ga]

\section{0}

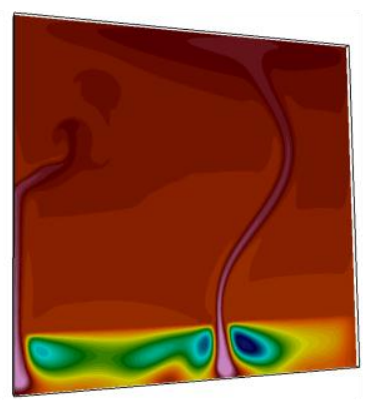

$500 \mathrm{~s}$

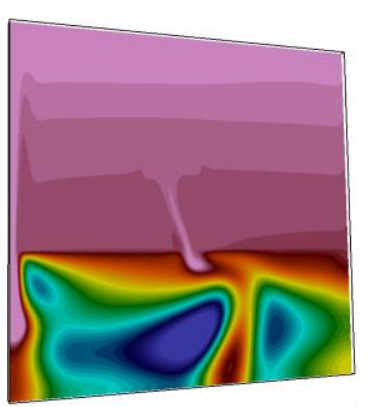

$1000 \mathrm{~s}$

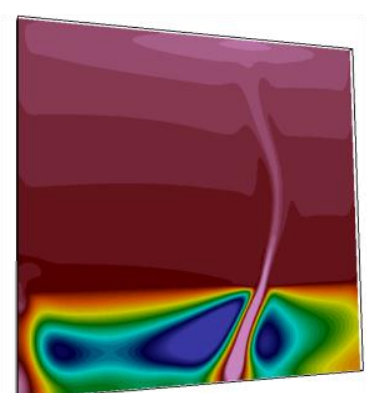

Solid fraction $[-]$
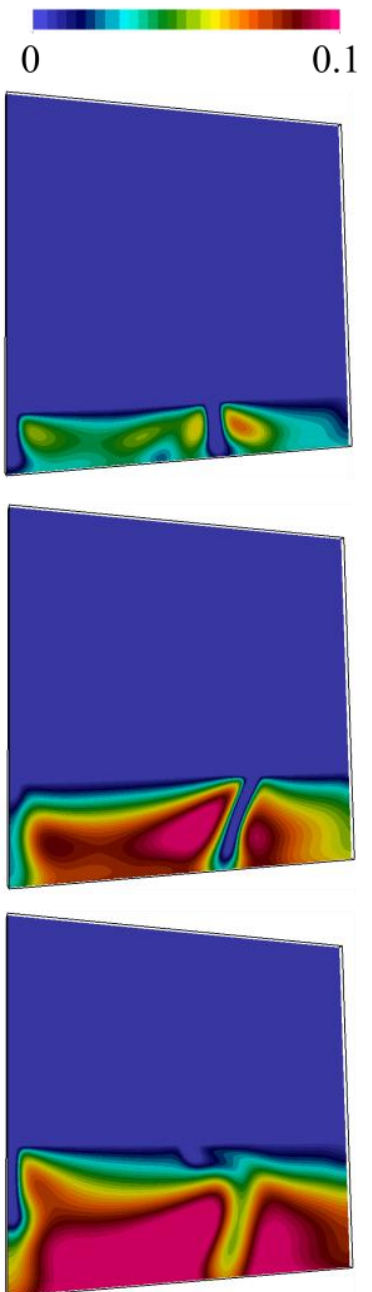

Superficial velocity $\left[\mathrm{ms}^{-1}\right]$
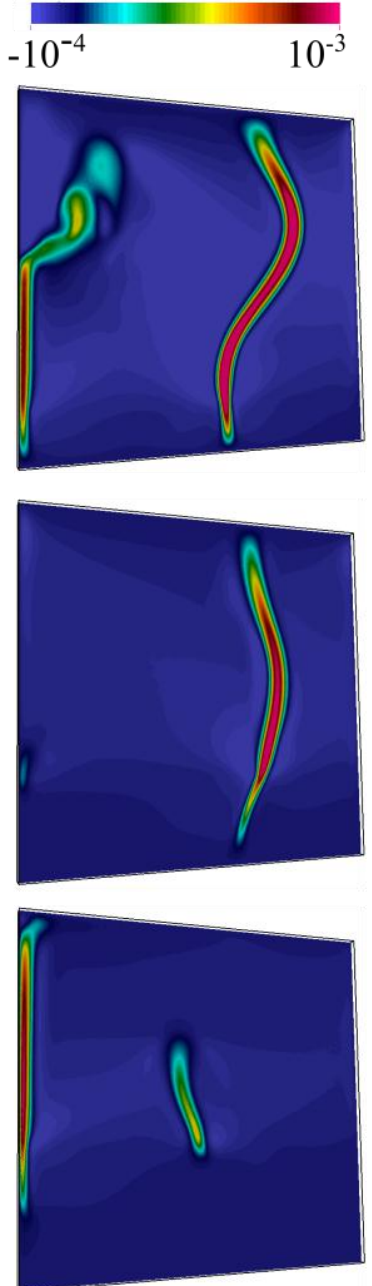

Temperature $\left[{ }^{\circ} \mathrm{C}\right]$

20

53
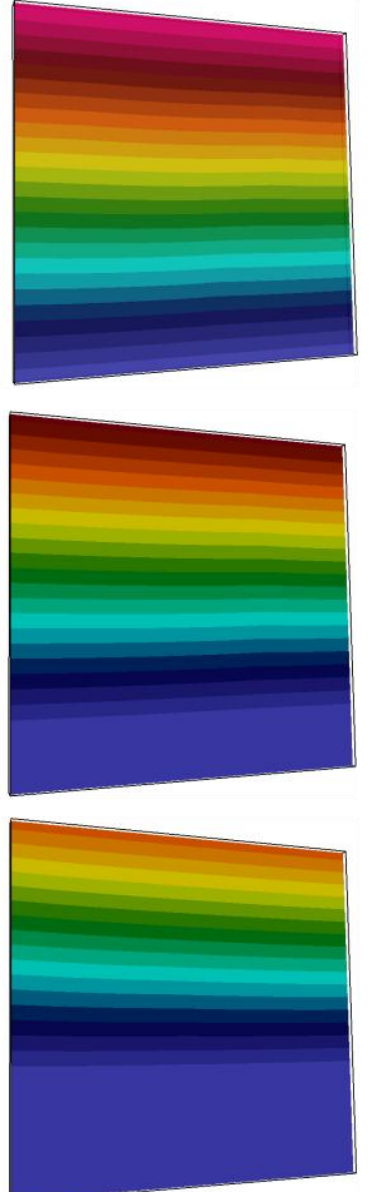

Figure 4: Simulation results for case FE_G2R1L1 showing, from left to right, maps of the average Ga composition, the solid fraction, the vertical component of the superficial velocity field and the temperature on a cut plane at the center of the cell at $500 \mathrm{~s}, 1000 \mathrm{~s}$ and $1500 \mathrm{~s}$. 
Composition [wt.\% Ga] 70
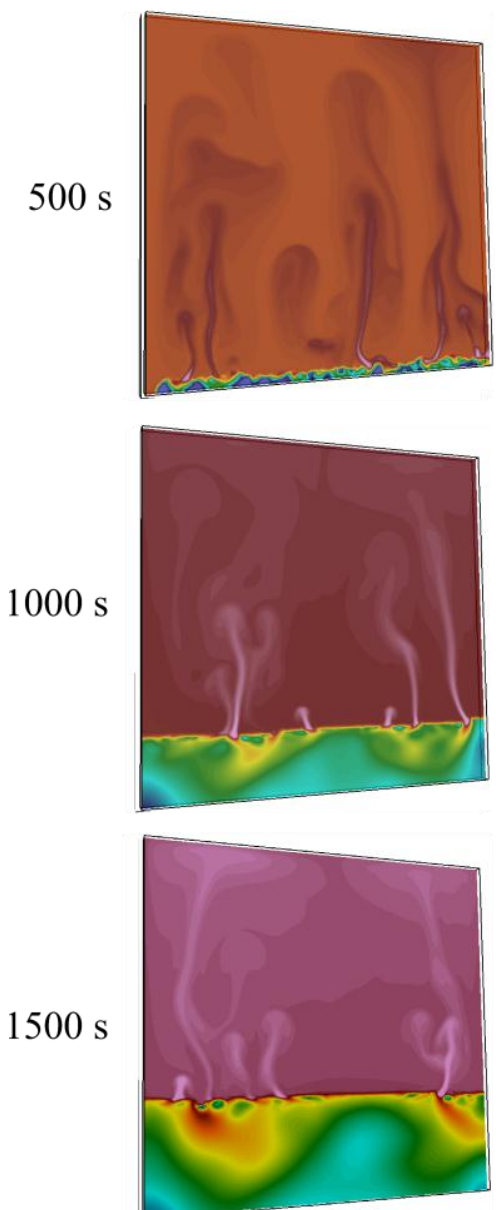

Solid fraction [-]

0
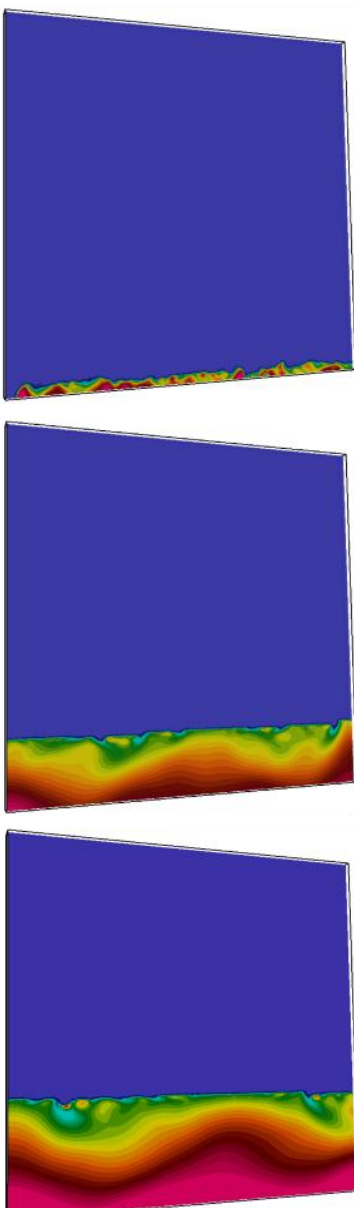

Superficial velocity $\left[\mathrm{ms}^{-1}\right]$
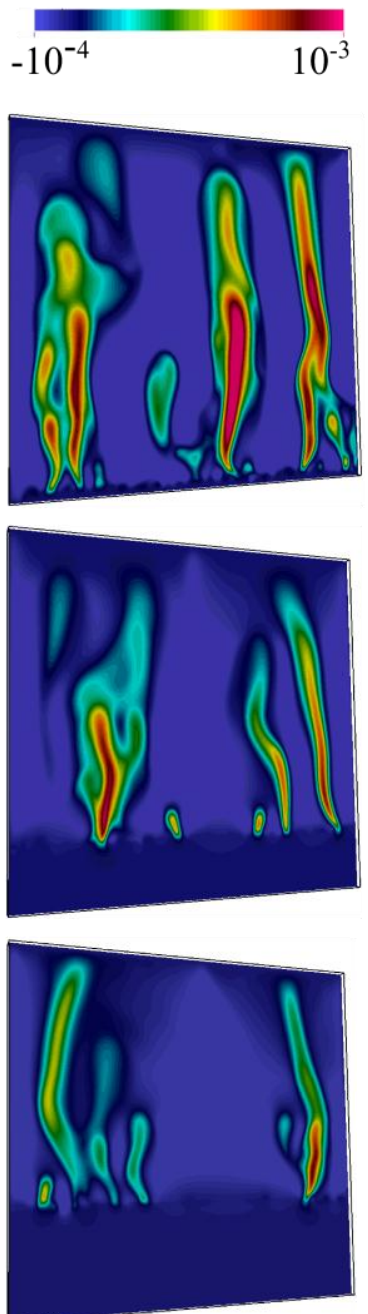

Temperature $\left[{ }^{\circ} \mathrm{C}\right]$ 20
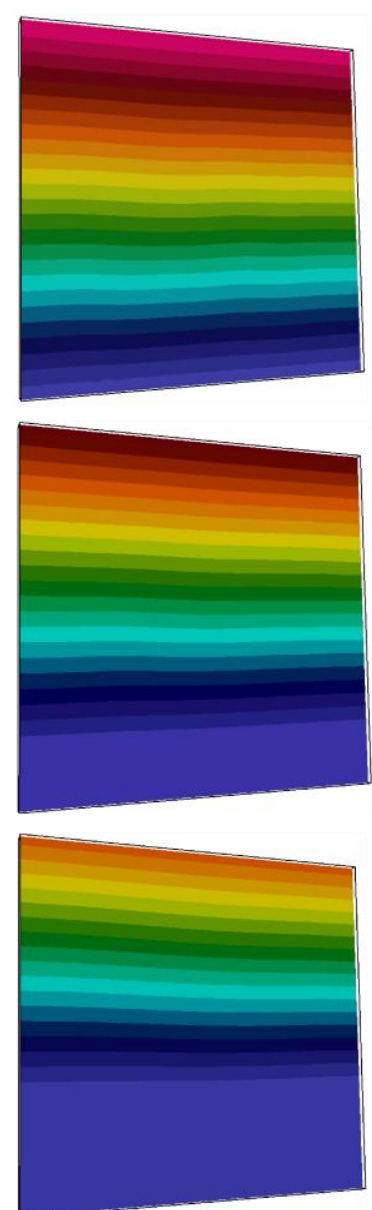

Grain structure [index] 므
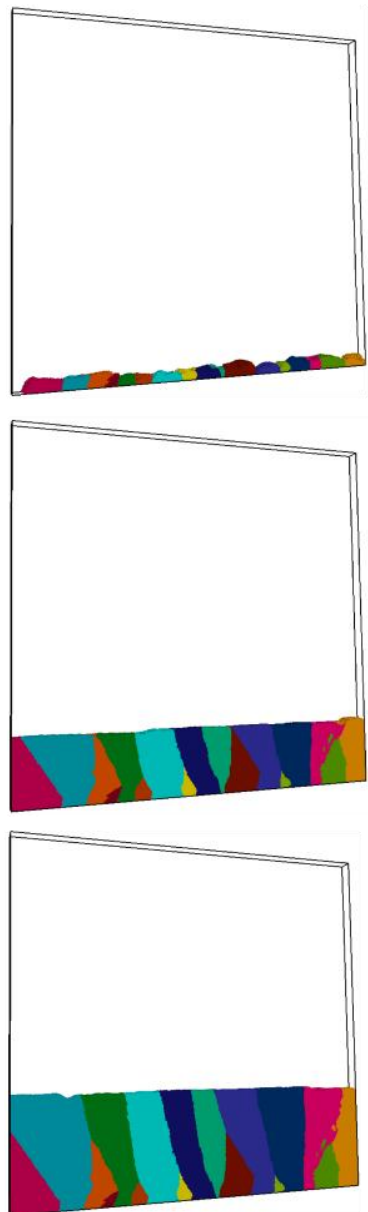

Figure 5: Results for CAFE_G2R1L1 case showing average composition, solid fraction, vertical component of the superficial velocity and temperature while the last column shows the grain envelopes predicted by the CAFE model. 


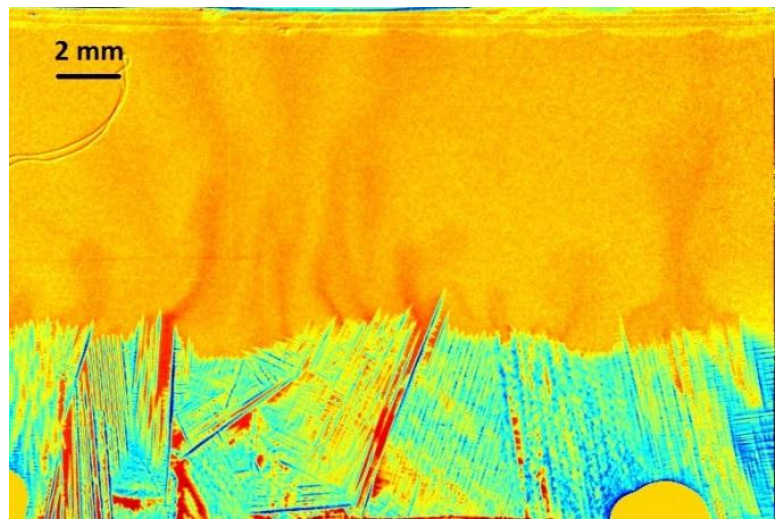

(a)

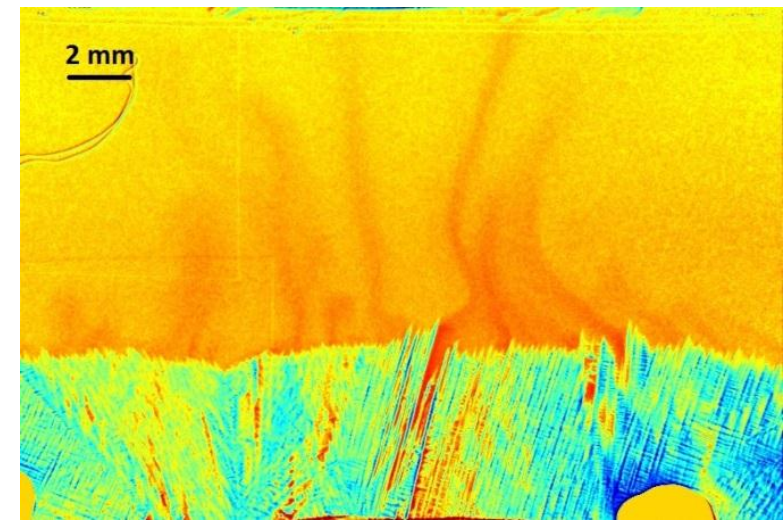

(b)

Figure 6: Snapshots of dendritic structure and composition field obtained from two solidification experiments at a cooling rate $R=-0.01 \mathrm{~K} \mathrm{~s}^{-1}$ and temperature gradients of (a) $\mathrm{G}=1.1 \mathrm{~K} \mathrm{~mm}^{-1}$ and (b) $\mathrm{G}=1.3 \mathrm{~K} \mathrm{~mm}^{-1}$ 
CAFE_G1R1L1 CAFE_G2R1L1

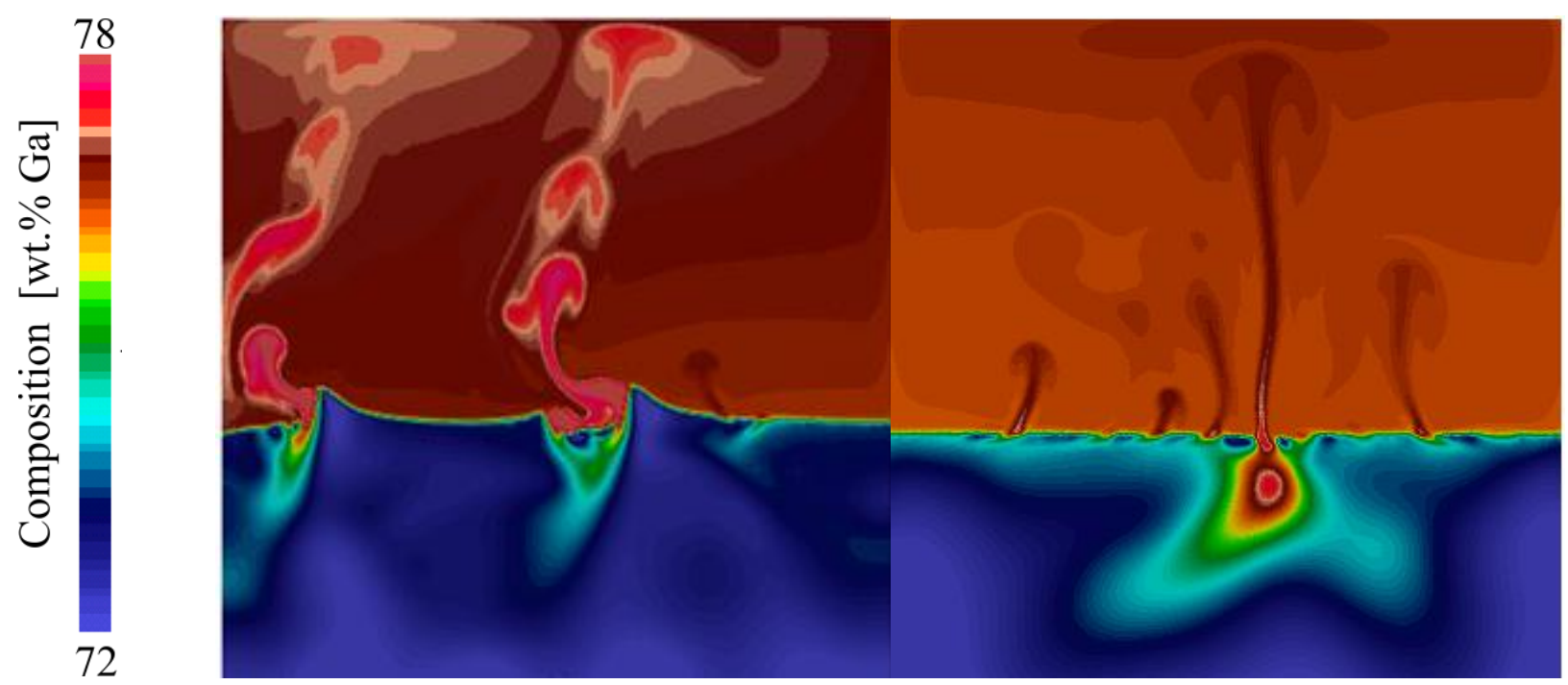

Figure 7: Average composition maps for CAFE_G1R1L1 at time $1060 \mathrm{~s}$ and CAFE_G2R1L1 at time $1845 \mathrm{~s}$ 


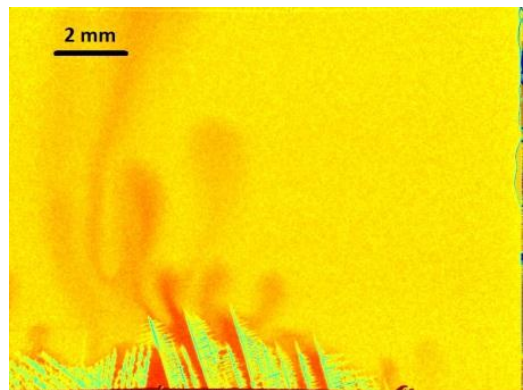

(a)

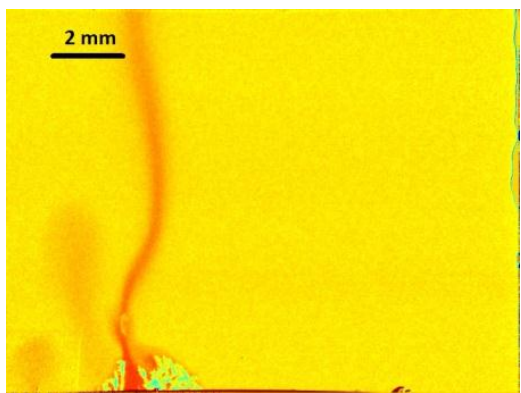

(b)

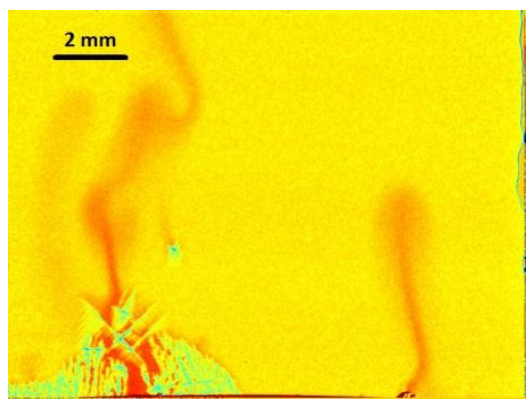

(c)

Figure 8: Snapshots of dendrite structure and composition field from two solidification experiments conducted at a cooling rate $R=-0.01 \mathrm{~K} \mathrm{~s}^{-1}$ and a temperature gradient $\mathrm{G}=1 \mathrm{~K} \mathrm{~mm}^{-1}$ : (a) "pulsing" plumes, (b) continuous plume, (c) upcoming instability of the plume 


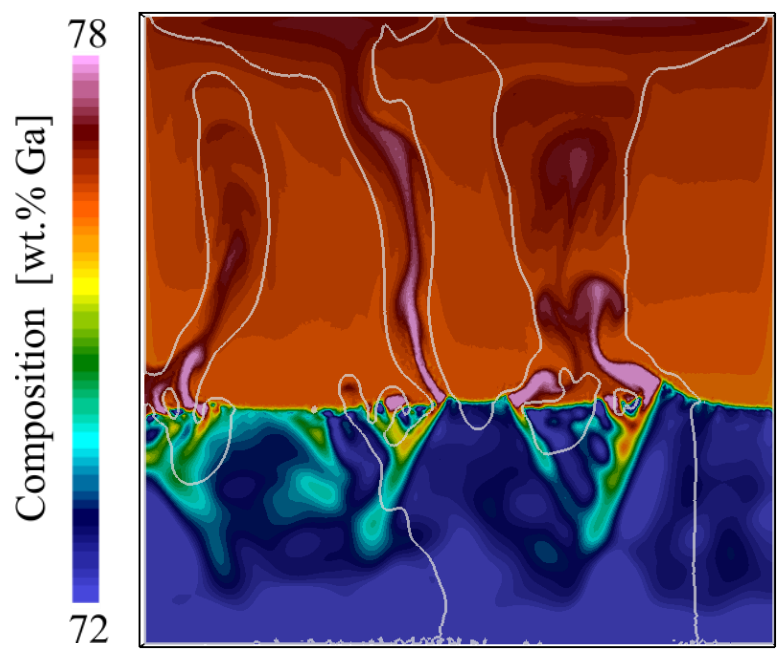

(a)

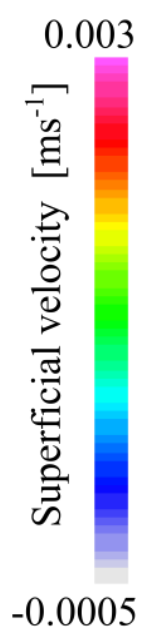

$-0.0005$

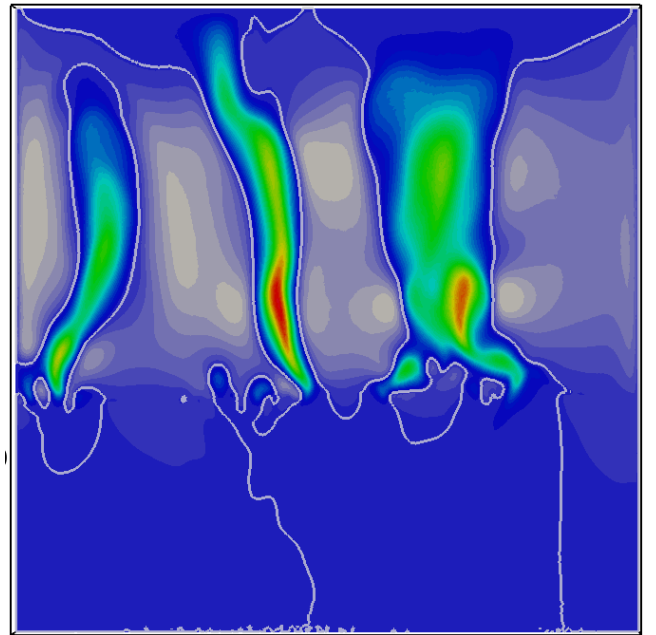

(b)

Figure 9: Results for case CAFE_G1R2L1 at 350 s showing (a) the average gallium composition and (b) the vertical component of the superficial velocity. The white contour identifies the zero velocity limit for the vertical component of the superficial velocity field. 


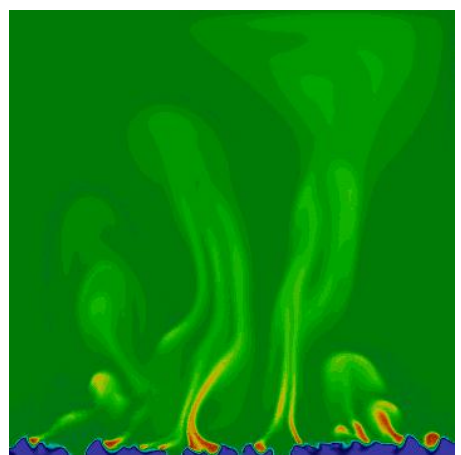

(a)

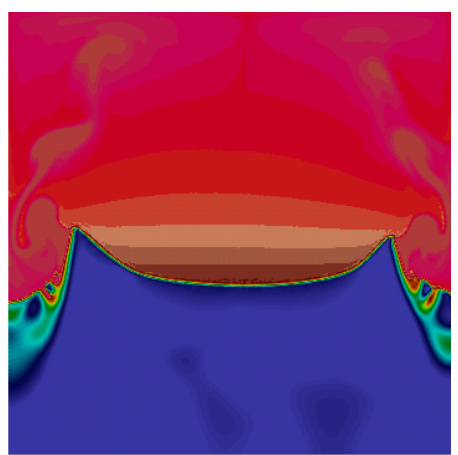

(b)

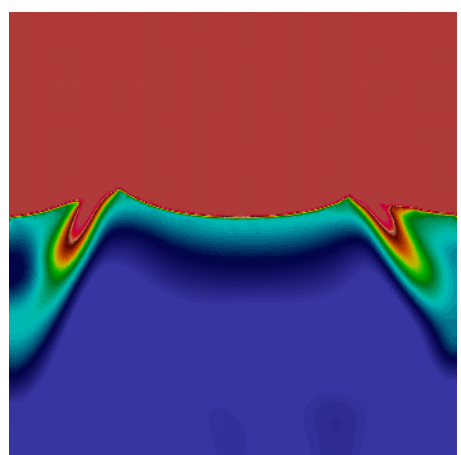

(c)

Figure 10: 2D cut plane of the average composition inside the cell for case CAFE_G1R1L2 at (a) $450 \mathrm{~s}$, (b) $1000 \mathrm{~s}$ and (c) $1500 \mathrm{~s}$ 


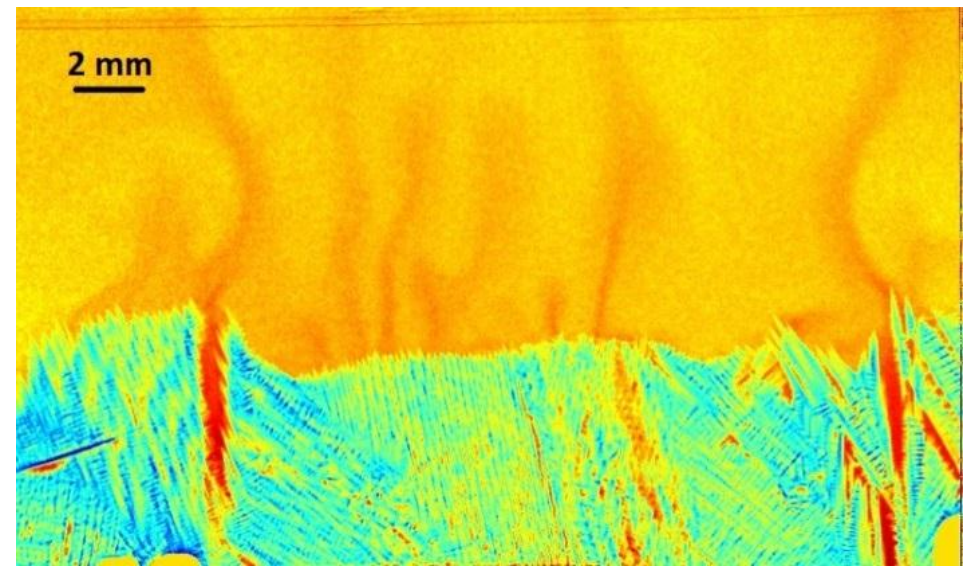

Figure 11: Snapshot of dendritic structure and composition field from a solidification experiment recorded at $1000 \mathrm{~s}$ for a cooling rate $R=-0.01 \mathrm{~K} \mathrm{~s}^{-1}$ and a temperature gradient $G=1 \mathrm{~K} \mathrm{~mm}^{-1}$ 


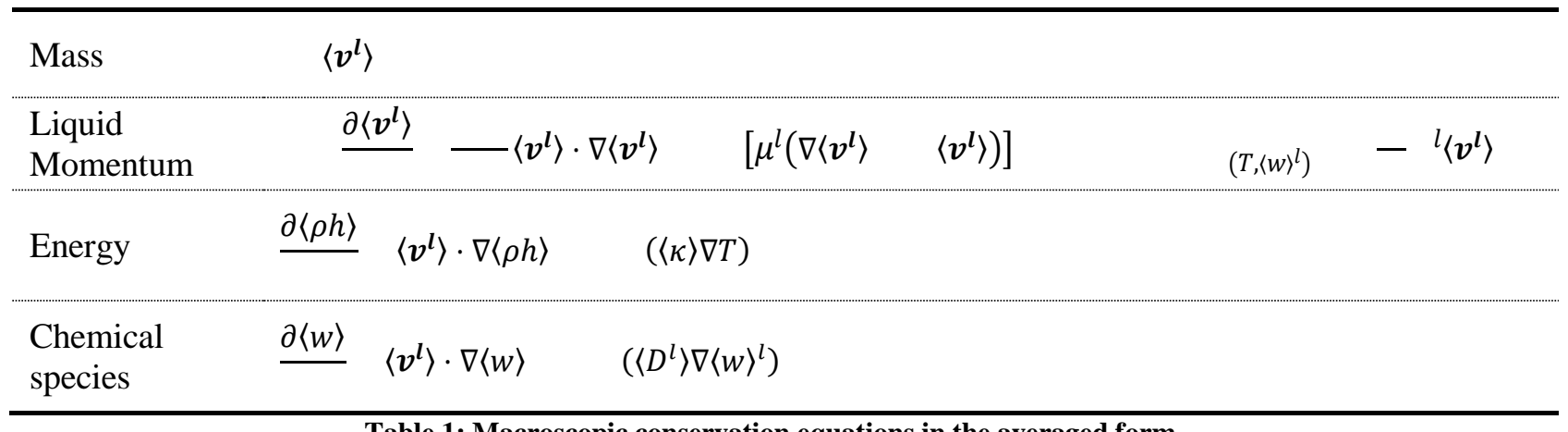

Table 1: Macroscopic conservation equations in the averaged form 


\begin{tabular}{llll}
\hline Parameter & Symbol & Value & Unit \\
\hline Nominal composition & $\left\langle w_{0}\right\rangle$ & 75 & $\mathrm{wt} \%$ \\
Liquidus temperature & $\mathrm{T}_{\mathrm{L}}$ & 25.25 & ${ }^{\circ} \mathrm{C}$ \\
Segregation coefficient & $\mathrm{k}$ & 0.0165 & $\mathrm{wt} \% / \mathrm{wt} \%$ \\
Liquidus slope & $\mathrm{m}_{\mathrm{L}}$ & -2.73 & ${ }^{\circ} \mathrm{C} \mathrm{wt} \%{ }^{-1}$ \\
\hline Gibbs-Thomson coefficient & $\Gamma$ & $2 \cdot 10^{-7}$ & ${ }^{\circ} \mathrm{C} \mathrm{m}^{-1}$ \\
Heat capacity (liquid and solid) & $\mathrm{c}_{\mathrm{p}}$ & 380.74 & $\mathrm{~J} \mathrm{~kg}^{-1} \mathrm{C}^{-1}$ \\
Enthalpy of fusion & $\mathrm{L}$ & $8.02 \cdot 10^{4}$ & $\mathrm{~J} \mathrm{~kg}^{-1}$ \\
Diffusion coefficient of Ga in liquid In & $\mathrm{D}^{1}$ & $1.525 \cdot 10^{-9}$ & $\mathrm{~m} \mathrm{~m}^{2} \mathrm{~s}^{-1}$ \\
Dynamic viscosity & $\mu^{1}$ & $2 \cdot 10^{-3}$ & $\mathrm{~Pa} \mathrm{~s}^{1}$ \\
Solutal expansion coefficient & $\beta_{\mathrm{w}}$ & $1.44 \cdot 10^{-3}$ & $\mathrm{wt} \%^{-1}$ \\
Thermal expansion coefficient & $\beta_{\mathrm{T}}$ & $0.0978 \cdot 10^{-3}$ & ${ }^{\circ} \mathrm{C}^{-1}$ \\
Density & & 6314.3 & $\mathrm{~kg} \mathrm{~m}^{-3}$ \\
Thermal conductivity in the solid & $\kappa^{\mathrm{s}}$ & 40 & $\mathrm{~W} \mathrm{~m}^{-1}{ }^{\circ} \mathrm{C}^{-1}$ \\
Thermal conductivity in the liquid & $\kappa^{1}$ & 28 & $\mathrm{~W} \mathrm{~m}^{-1} \mathrm{C}^{-1}$ \\
Dendrite arm spacing & $\lambda$ & $60 \cdot 10^{-6}$ & $\mathrm{~m} \mathrm{~m}$ \\
\hline Cell size & & $30 \cdot 10^{-6}$ & $\mathrm{~m}$ \\
FE mesh size & & $140 \cdot 10^{-6}$ & $\mathrm{~m}$ \\
Time step & & 0.1 & $\mathrm{~s}$ \\
\hline
\end{tabular}

Table 2: Material parameters for In - 75 wt.\% Ga and numerical parameters 


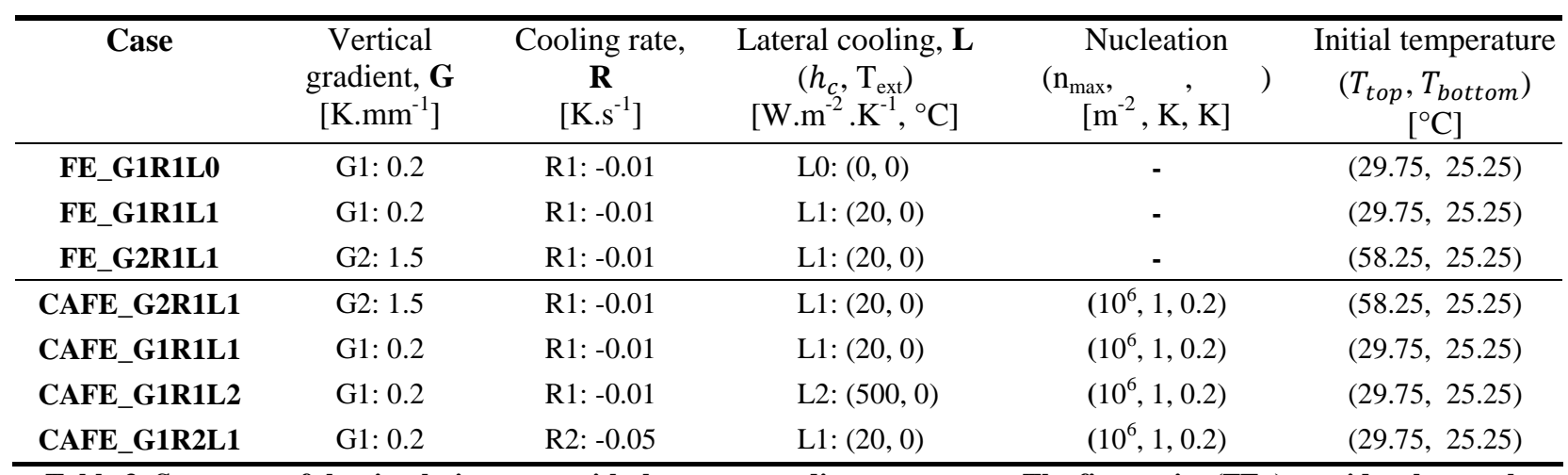

Table 3: Summary of the simulation cases with the corresponding parameters. The first series (FE_) consider the purely macroscopic model while the second series (CAFE_) makes use of the coupling with the grain structure model. Parameters are varied from (G1) low to (G2) high gradient, (R1) low to (R2) high cooling rate and (L0) no, (L1) low and (L2) high lateral cooling. 